\title{
Aplikasi Web Augmented Reality Villa
}

\author{
Gede Yudha Prema Pangestu, Ni Made Ika Marini Mandenni, Ni Kadek Dwi Rusjayanthi \\ Jurusan Teknologi Informasi Fakultas Teknik Universitas Udayana \\ Bukit Jimbaran, Bali, Indonesia, telp. 0361701806 \\ e-mail: yudhaprema@gmail.com, made.ika.mm@gmail.com,dwi.rusjayanthi@unud.ac.id
}

\begin{abstract}
Abstrak
Bali merupakan salah satu tujuan wisata yang sangat berkembang di Indonesia. Kedatangan wisatawan yang berlibur ke Bali menyebabkan meningkatnya kebutuhan hunian lengkap dengan fasilitasnya. Tingkat hunian hotel ataupun villa di Bali cenderung meningkat drastis pada saat liburan panjang. Munculnya hunian hotel dan villa baru saat ini menimbulkan tingkat persaingan bagi pelaku usaha, sehingga dibutuhkan sebuah ketepatan penggunaan strategi komunikasi pemasaran yang baik dalam memasarkan produk agar dapat menarik perhatian konsumen. Aplikasi Web Augmented Reality Villa dapat membantu memvisualisasikan hunian villa dalam bentuk 3-dimensi sehingga terlihat lebih menarik dan praktis. Penggunaan brosur sebagai informasi tertulis dan penerapan teknologi augmented reality pada Aplikasi Web Augmented Reality Villa bertujuan untuk membangun suatu aplikasi yang dapat memberikan informasi mengenai villa kepada pengunjung. Pengembangan Aplikasi Web Augmented Reality Villa menggunakan library FlarToolkit. Berdasarkan hasil pengujian menunjukkan aplikasi dapat menampilkan objek 3-dimensi villa dengan melakukan scanning marker pada brosur yang sudah berisi marker.
\end{abstract}

Kata kunci: augmented reality, marker, 3 dimensi, brosur, villa

\begin{abstract}
Bali is one of the highly developed tourist destination in Indonesia. The arrival of tourists having holiday in Bali led to increase residential needs with complete amenities. The occupancy rate of hotel and villa in Bali is increase significantlly during the long vacation. The emergence of new villa and hotel occupancy raises the level of competition in business, so it needs a correct use good marketing communication strategy in marketing the product in order to attract the attention of consumers. Web Application Augmented Reality Villa can help visualize the residential villa in three-dimensional shapes that look more attractive and practical. The use of brochures as written information and the application of augmented reality technology on the Web Application Augmented Reality Villa aims to develop an application that can provide information about the villa to visitors. Web Application uses Augmented Reality Villa designed by FlarToolkit library. Based on the test results show the application can display 3-dimensional objects by scanning marker villa in a brochure which already contain marker.
\end{abstract}

Keywords: augmented reality, marker, 3 dimension, brochure, villa

\section{Pendahuluan}

Bali merupakan salah satu tujuan wisata yang sangat berkembang di Indonesia, tidak hanya alam dan budayanya yang menjadi kelebihan dari Bali tetapi karakter dan perilaku masyarakat yang sangat menghormati satu sama lain, ramah terhadap sesama dan pendatang, sangat religius, dan bersama-sama berusaha menjaga citra pulau Bali yang sudah dikenal pasar nasional maupun internasional. Jutaan wisatawan asing maupun wisatawan lokal berdatangan tiap tahunnya ke pulau Bali. Kedatangan wisatawan yang berlibur ke Bali membutuhkan hunian dengan segala kelengkapan fasilitas. Hampir semua hotel mendulang untung di masa liburan. Para pelaku usaha hotel dan villa bersaing ketat untuk menarik pengunjung dan meraup untung sebesar-besarnya [1].

Munculnya hunian hotel dan villa baru saat ini menimbulkan tingkat persaingan bagi pelaku usaha, sehingga dibutuhkan sebuah ketepatan penggunaan strategi komunikasi pemasaran yang baik dalam memasarkan produk agar dapat menarik perhatian konsumen. 
Selama ini, brosur digunakan sebagai salah satu media pemasaran hunian hotel atau villa pada umumnya. Informasi pada brosur umumnya hanya menampilkan gambar dan teks sehingga terkesan monoton. Berdasarkan hal tersebut penulis memiliki ide untuk memanfaatkan keunggulan augmented reality sebagai penunjang media pemasaran dan informasi hunian di Bali khususnya hunian villa.

Augmented reality adalah penggabungan dunia nyata dan virtual, bersifat interaktif secara real time, dan bentuknya merupakan animasi 3-dimensi. Interaktif yang dimaksud adalah adanya interaksi dari user ke augmented reality tersebut. Augmented reality atau yang biasa disebut dengan AR bukan merupakan teknologi baru. Pertama kali ide augmented reality diterapkan pada buku dengan nama Magic Book yang diteliti oleh Bilinghurst dan penelitian selanjutnya dilakukan oleh Grasset dengan menambahkan fitur multimedia untuk ditampilkan pada augemented reality sebagai pelengkap objek 3-dimensi dengan menggunakan library ARToolkit (M. Billinghurst, 2001). Abdur Rahman melakukan penelitian dengan judul "Rancang Bangun Aplikasi Informasi Universitas Bengkulu Sebagai Panduan Pengenalan Kampus Berbasis Android" pada Tahun 2014 mengenai teknik markerless (tanpa marker) Seiring berjalannya waktu, augmented reality berkembang sangat pesat sehingga memungkinkan pengembangan aplikasi ini diberbagai bidang termasuk pada bidang bisnis hunian [2] [6] [7].

Keunggulan augmented reality dimanfaatkan pada penelitian ini untuk membantu memvisualisasikan konsep abstrak lebih intuitif untuk meningkatkan pemahaman dalam menggambarkan suatu model objek. Augmented reality diterapkan dalam website pemasaran sebuah villa, bertujuan agar villa dapat ditampilkan dalam bentuk objek 3-dimensi sehingga terlihat lebih menarik dan praktis. Augmented reality dibangun berbasis web sehingga lebih efisien karena dapat diakses tanpa harus melakukan instalasi aplikasi terlebih dahulu.

\section{Metodologi dan Perancangan Sistem}

\subsection{Gambaran Umum Sistem}

Aplikasi web augmented reality Villa merupakan rancangan aplikasi yang bertujuan sebagai sarana penunjang media promosi pada sebuah website villa. Aplikasi dibangun dengan library FlarToolkit untuk mendukung rendering pada web dan selanjutnya menampilkan objek 3-dimensi. Aplikasi berjalan pada sebuah website villa, dan pengunjung dapat melakukan scanning marker pada website tersebut. Diagram use case membantu menjelaskan mekanisme yang terjadi pada website. Use case adalah diagram yang menunjukkan fungsionalitas suatu sistem atau kelas dan bagaimana sistem tersebut berinteraksi dengan dunia luar dan menjelaskan sistem secara fungsional yang terlihat oleh user. Mekanisme lebih jelasnya dapat dilihat pada Gambar 1.

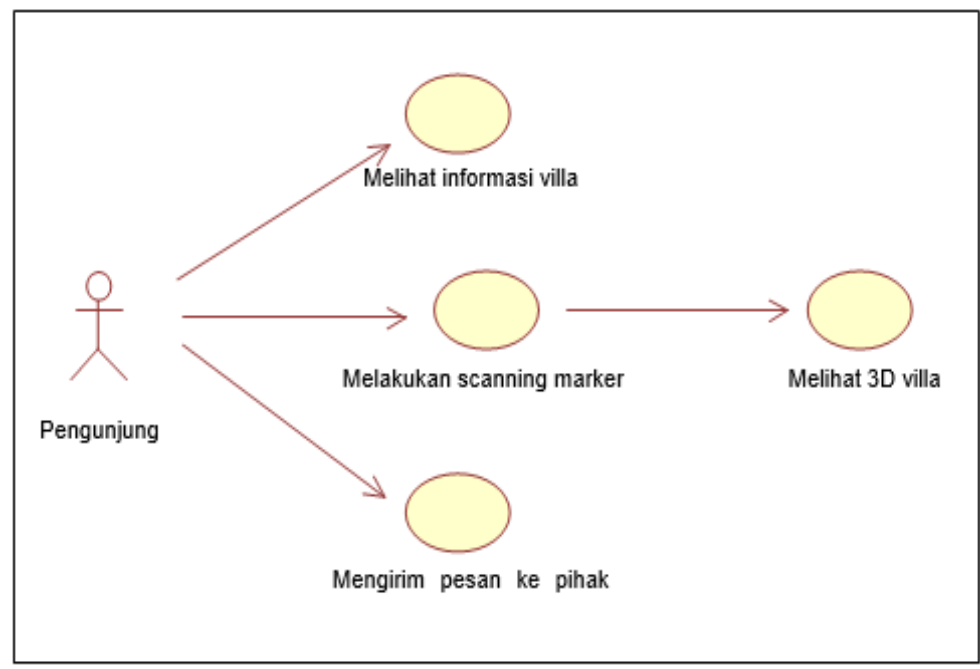

Gambar 1. Diagram Use case.

Alur yang terdapat pada Gambar 1 merupakan gambaran umum dari rancangan sistem aplikasi web augmented reality villa ini secara keseluruhan. Halaman Home, Scan Marker, Services, Rooms, Gallery, dan Contact, terdapat pada website villa. Pengunjung disuguhkan dengan informasi villa di setiap halaman yang disediakan. Pengunjung dihadapkan dengan 
ruang untuk menampilkan video dari webcam pada halaman scan marker. Pengunjung dapat melakukan scanning marker pada halaman ini dengan menghadapkan marker pada webcam untuk menampilkan objek 3-dimensi villa.

\subsection{Rancangan Sistem}

Tahapan setelah melakukan analisis gambaran umum aplikasi adalah perancangan sistem aplikasi. Pembuatan aplikasi ini perlu dicermati bagaimana menciptakan sebuah aplikasi yang bersifat user friendly, yaitu user selaku pengguna aplikasi dapat dengan mudah dan mengerti menggunakan aplikasi yang dibuat.

a. Struktur Flowchart Aplikasi

Struktur flowchart berfungsi untuk mendefinisikan dan mengilustrasikan alur kerja sistem sekaligus sebagai struktur dasar perancangan aplikasi web augmented reality Villa. Struktur dapat dilihat pada Gambar 2.

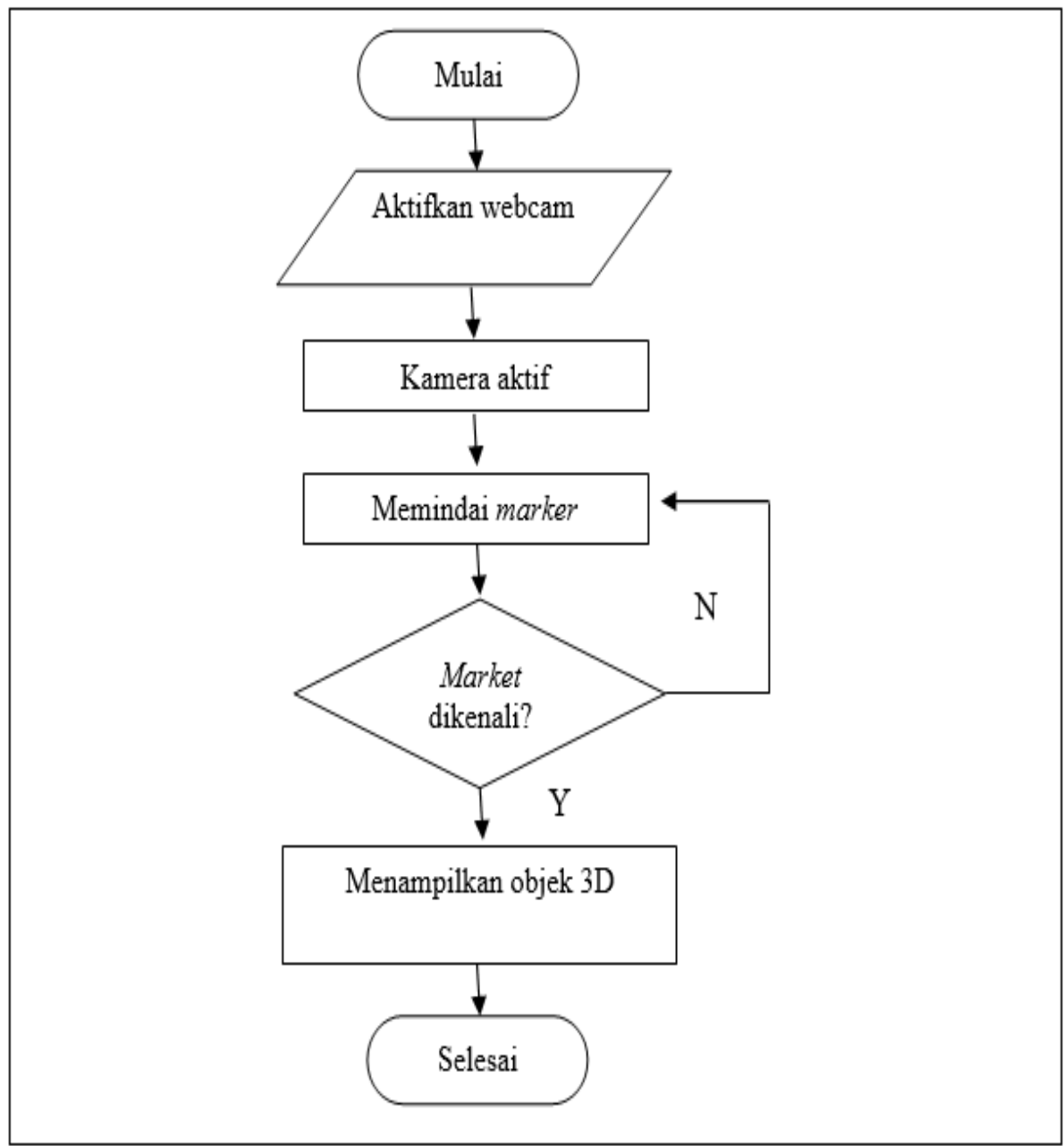

Gambar 2. Struktur Flowchart Aplikasi

Aplikasi web augmented reality Villa menggunakan library FlarToolkit sebagai library augmented reality yang dijadikan tempat untuk menyimpan dan mengolah objek 3dimensi dan identifikasi pelacakan pada perangkat kamera. Aplikasi melakukan pendeteksian melalui kamera webcam untuk mendeteksi marker, kemudian menampilkan objek 3-dimensi (render) bangunan villa apabila ditemukan penanda yang dikenali. Gambar 2 menunjukkan alur flowchart aplikasi, ketika kamera aktif secara otomatis sistem memindai marker pada gambar yang ditangkap, apabila marker terdeteksi maka sistem menampilkan objek 3-dimensi villa tepat di atas marker. 
b. Activity Diagram Menu Scan Marker

Activity diagram menggambarkan bagaimana interaksi antara pengguna atau user dengan sistem ketika masuk ke halaman utama web dan melakukan scan marker. Gambar 3 merupakan activity diagram menu scan marker.

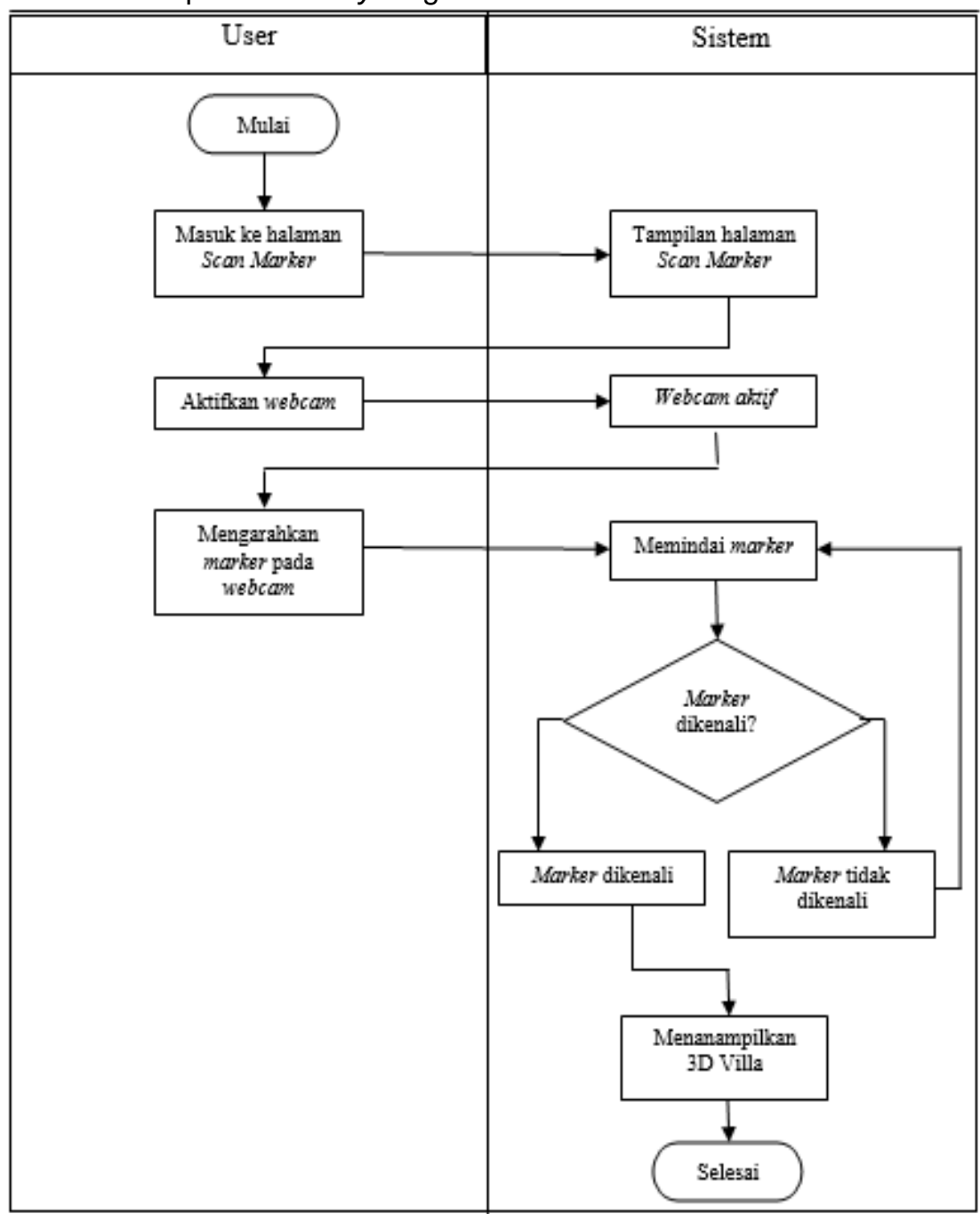

Gambar 3. Activity Diagram Menu Scan Marker

Gambar 3 menunjukkan diagram aktivitas antara user dan sistem pada menu scan marker. User masuk ke halaman Scan Marker dan mengaktifkan wabcam, maka kamera wabcam pada sistem aktif. User mengarahkan marker yang terdapat pada brosur ke arah wabcam. Sistem memindai marker, jika marker dikenali maka sistem menampilkan 3-dimensi villa dan apabila marker tidak dikenali maka sistem kembali melacak marker.

\subsection{Rancangan Antarmuka}

Rancangan antarmuka (Interface) merupakan rancangan awal dari tampilan website villa. Rancangan antarmuka ini ditujukan untuk mempermudah pembuatan antarmuka dari sistem. Rancangan yang dibuat bersifat user friendly dimana bertujuan agar pengguna merasa tertarik, nyaman, dan mudah dalam menggunakannya. Rancangan antarmuka website adalah sebagai berikut.

a. Rancangan Antarmuka Halaman Utama

Halaman utama merupakan halaman yang tampil ketika pengunjung memasukkan alamat website pada address bar. Pengunjung dapat melihat menu website, layanan, 
aktivitas, photo slide, serta informasi kontak villa. Rancangan antarmuka halaman utama dapat dilihat pada Gambar 4.

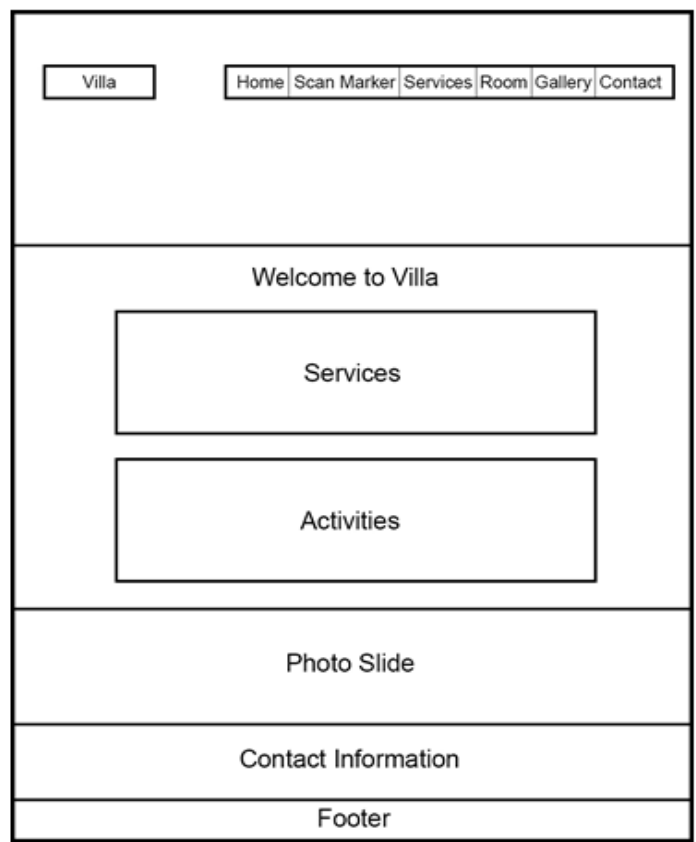

Gambar 4. Rancangan Antarmuka Halaman Home

Rancangan antarmuka halaman utama pada Gambar 4, pengunjung dapat melihat menu website, layanan, aktivitas, photo slide, serta informasi kontak villa.

b. Rancangan Antarmuka Halaman Scan Marker

Halaman scan marker merupakan halaman yang tampil ketika pengunjung menekan tombol scan marker. Pengunjung dapat melakukan scanning marker dengan menggunakan marker yang terdapat pada brosur villa. Rancangan antarmuka halaman scan marker dapat dilihat pada Gambar 5.

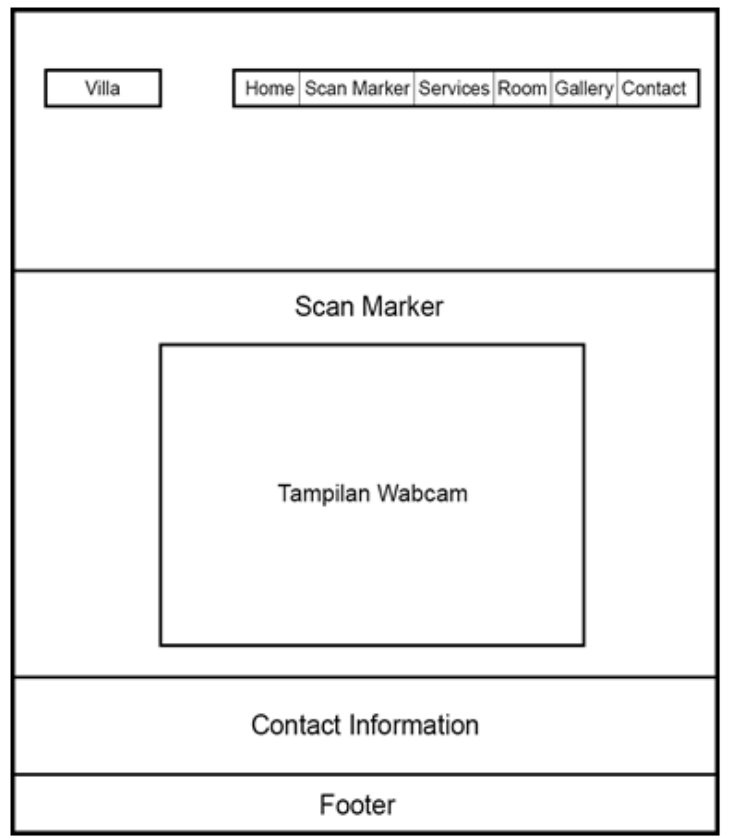

Gambar 5. Rancangan Antarmuka Halaman Scan Marker 
Rancangan antarmuka halaman scan marker pada Gambar 5, pengunjung dapat melakukan scanning marker dengan menggunakan marker yang terdapat pada brosur villa.

\subsection{Perancangan Objek 3-dimensi Villa}

Perancangan objek 3-dimensi villa adalah tentang perancangan objek villa dalam bentuk 3-dimensi yang ditampilkan dalam web. Objek 3-dimensi villa dibuat menggunakan software Google SketcUp. Perancangan 3-dimensi villa dimensi melalui cukup banyak tahapan agar dapat menghasilkan bentuk objek 3-dimensi yang baik, Gambar 6 menunjukkan hasil perancangan objek 3-dimensi villa.

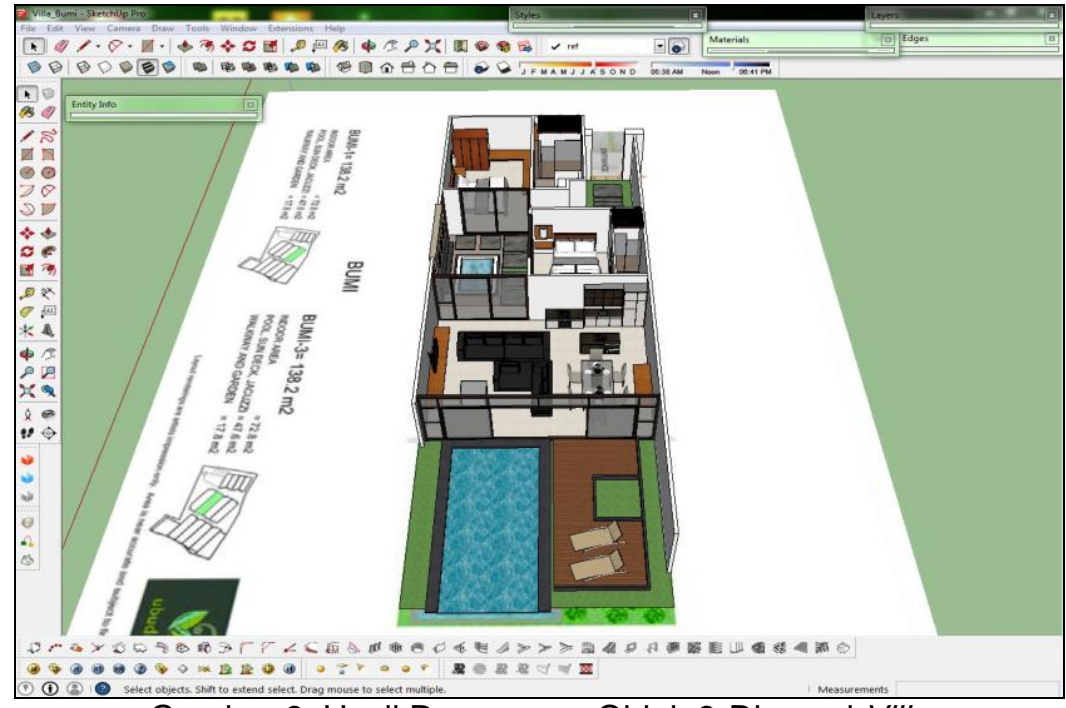

Gambar 6. Hasil Rancangan Objek 3-Dimensi Villa

Gambar 6 menunjukkan hasil rancangan objek 3-dinemsi villa, perancangan objek 3dimensi villa menggunakan software Google SketcUp. Objek 3-dimensi villa dibangun tanpa atap agar interior dan exterior villa dapat terlihat.

\subsection{Desain dan Pembuatan Brosur}

Brosur yang dibuat berfungsi sebagai media promosi sekaligus sebagai media untuk penempatan marker. Beberapa halaman terdapat pada brosur, antara lain: cover, profile, location, villa, activity, dan restaurant. Perancangan brosur dibuat menggunakan Adobe Photoshop CS 5. Gambar 7 merupakan hasil perancangan brosur.

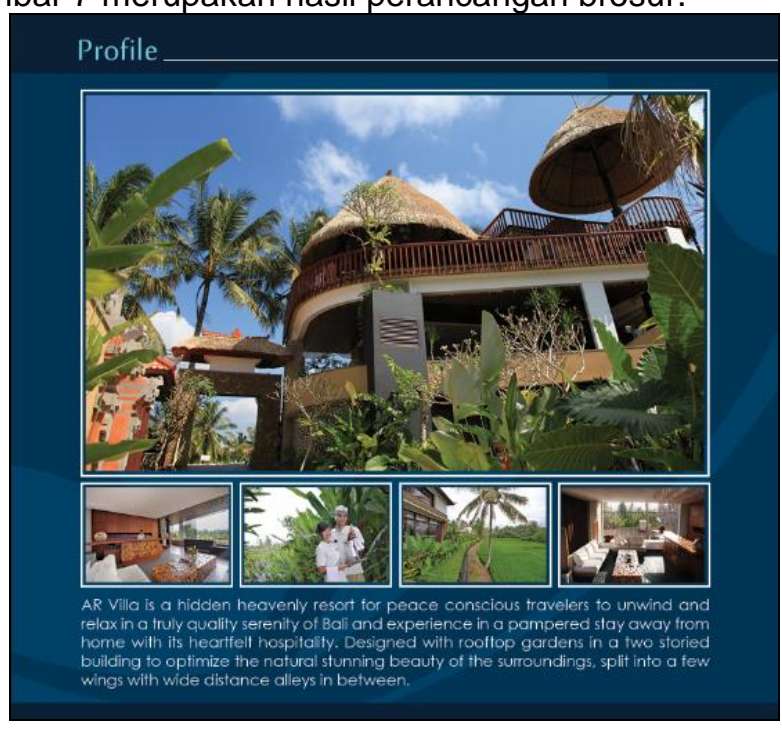




\section{Gambar 7. Hasil Rancangan Brosur}

Gambar 7 menunjukkan hasil pembuatan brosur, brosur dibuat menggunakan Adobe Photoshop CS 5. Brosur juga berfungsi sebagai media penempatan marker, selain sebagai media penyajian informasi villa.

\subsection{Desain dan Pembuatan Marker}

Marker didesain sedemikian rupa agar dapat dideteksi dengan mudah oleh sistem pada aplikasi. Marker yang dibuat diinput ke sistem dengan menggunakan aplikasi marker generator. Gambar 8 merupakan hasil pembuatan marker.

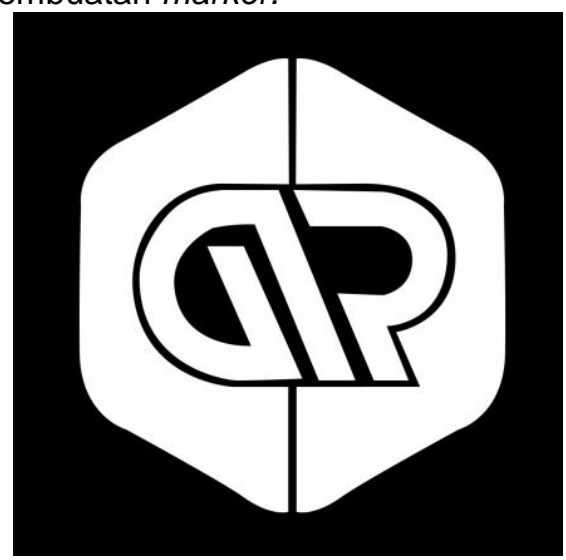

Gambar 8. Hasil Pembuatan Marker

Gambar 8 adalah desain marker yang digunakan sebagai penanda untuk aplikasi augmented reality. Marker yang dibuat di-input ke sistem dengan menggunakan aplikasi marker generator.

\section{Kajian Pustaka}

\subsection{State Of The Art Review}

Pengembangan Augmented Reality pada buku selanjutnya berhasil diterapkan pada smartphone oleh Bauset dengan teknik fiduciary marker berbentuk gambar persegi hitam seperti QR code atau barcode, menggunakan library ARToolkitplus yang memunculkan objek 3dimensi (3D) dari buku pelajaran yang juga menguji kecepatan dalam mengenali marker oleh perangkat Android dan iOS [3].

\subsection{Augmented reality}

Augmented reality adalah penggabungan antara objek virtual dengan objek nyata. Sebagai contoh, adalah saat pembawa acara televisi membawakan berita, ada animasi atau objek virtual yang ikut bersamanya, jadi seolah-seolah pembawa acara berada didalam dunia virtual tersebut, padahal sebenarnya adalah tehnik penggabungan antara dunia virtual dengan dunia nyata yang dinamakan dengan augmented reality. Augmented reality adalah menggabungakan dunia nyata dan virtual, bersifat interaktif secara real time, dan bentuknya merupakan animasi 3-dimensi. Interaktif disini yang dimaksud adalah adanya interaksi dari user ke augmented reality tersebut [2].

\subsection{Google Sketchup}

Google SketchUp adalah program grafis 3-dimensi yang dikembangkan oleh Google yang mengombinasikan seperangkat alat (tools) yang sederhana, namun sangat handal dalam desain grafis 3-dimensi di dalam layar komputer. Program grafis ini berhasil menjadi pendatang baru di dunia grafis 3-dimensi yang disegani dan mampu menyamai keunggulan berbagai perangkat lunak grafis 3-dimensi lainnya yang terlebih dahulu dikenal. Selain fitur-fiturnya yang user friendly, Google SketchUp juga tersedia secara gratis (kecuali untuk versi Pro) bagi semua orang yang tertarik untuk mempelajari dunia grafis 3-dimensi, sesuai dengan tagline yang diembannya, yakni '3D Modelling for Everyone' [4]. 


\subsection{Adobe Flash}

Adobe Flash merupakan sebuah program yang didesain khusus oleh Adobe dan program aplikasi standar authoring tool professional yang digunakan untuk membuat animasi dan bitmap yang sangat menarik untuk keperluan pembangunan aplikasi maupun situs web yang interaktif dan dinamis. Keunggulan yang dimiliki oleh Flash ini adalah mampu diberikan sedikit kode pemograman baik yang berjalan sendiri untuk mengatur animasi yang ada didalamnya atau digunakan untuk berkomunikasi dengan program lain seperti HTML, PHP, dan Database dengan pendekatan $X M L$, dapat dikolaborasikan dengan web, karena mempunyai keunggulan antara lain kecil dalam ukuran file output-nya [5].

\section{Pengujian Dan Analisia Hasil}

\subsection{Gambaran Umum Aplikasi}

Aplikasi augmented reality yang diimplementasikan pada website villa, diakses oleh satu pengguna (single user), pengguna adalah pengunjung villa. Pengguna dapat menggunakan aplikasi ini dengan media brosur atau marker yang sudah disiapkan di dalam brosur villa. Secara umum alur sistem aplikasi yang dibuat adalah sebagai berikut :

a. Pengguna membuka website villa yang sudah dilengkapi dengan fitur aplikasi Augmented Reality.

b. Pengguna menyiapkan brosur villa yang dijadikan sebagai marker atau penanda.

c. Pengguna mengarahkan webcam ke hadapan marker sehingga secara otomatis aplikasi melacak marker (penanda) tersebut dan kemudian memunculkan miniature villa dalam bentuk 3 dimensi.

d. Pengguna dapat berinteraksi dengan objek 3 dimensi dengan cara menggerakkan brosur villa.

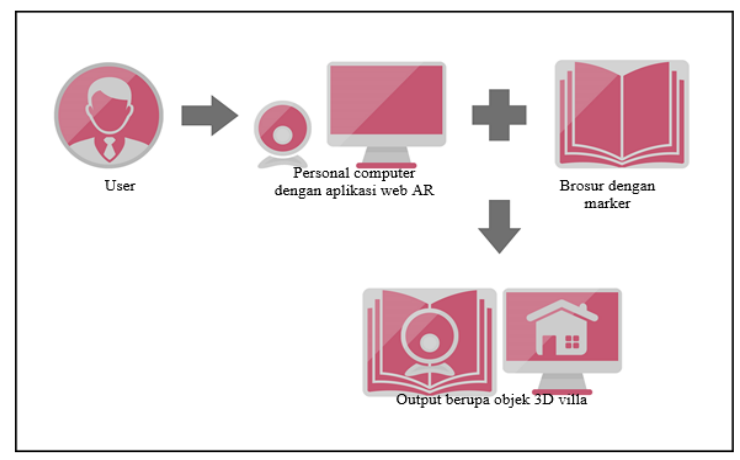

Gambar 9. Gambaran Umum Penggunaan Aplikasi Augmented Reality Villa.

Gambaran umum aplikasi pada Gambar 9 memperlihatkan interaksi yang terjadi antara pengguna dengan aplikasi web augmented reality villa dimana pengguna dapat berinteraksi langsung dengan website villa pada perangkat komputer. Pengguna masuk ke halaman scan marker dan mengaktifkan webcam, kemudian webcam diarahkan ke marker yang terdapat pada brosur villa. User dapat melihat objek 3-dimensi villa yang merupakan output dari aplikasi, setelah marker diidentifikasi.

\subsection{Rancangan Antarmuka}

Rancangan antarmuka ditujukan untuk mempermudah pembuatan antarmuka dari sistem. Rancangan yang dibuat bersifat user friendly dimana bertujuan agar pengguna merasa tertarik, nyaman, dan mudah dalam menggunakannya. Tampilan halaman utama (home) dari media informasi berbasis web terdiri atas header, menu utama, services informations, dan footer. Menu utama terdiri atas Home, Scan Marker, Services, Rooms, Gallery, Contact. Informasi tentang layanan villa yang disediakan terdapat pada ruang services informations. Tampilan halaman utama dari web villa dapat dilihat pada Gambar 10. 


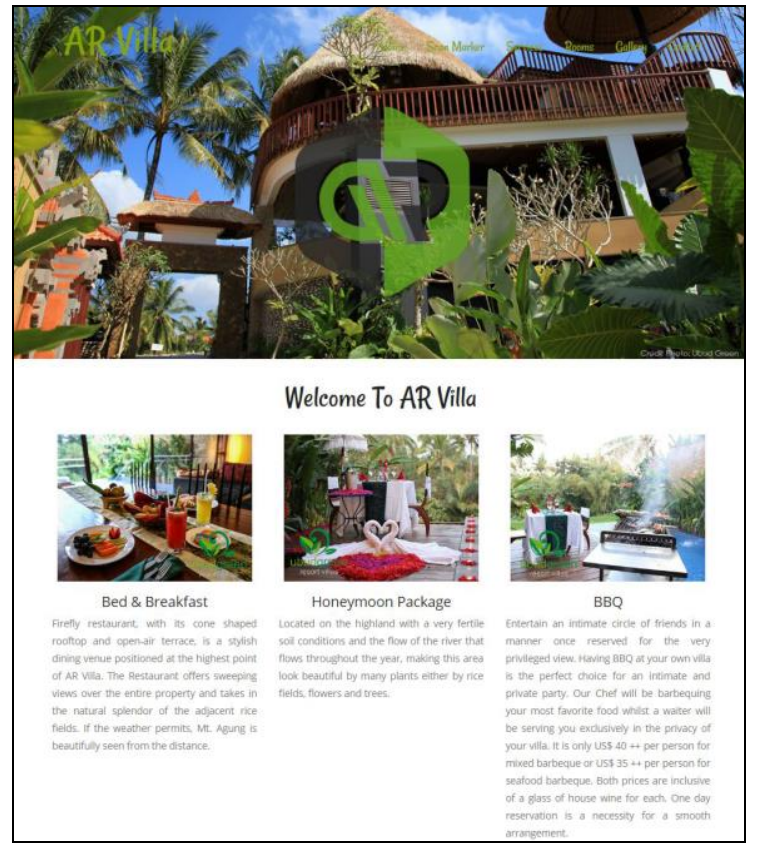

Gambar 10. Gambaran Umum Penggunaan Aplikasi Augmented Reality Villa.

Gambar 10 menunjukkan tampilan halaman utama. Pengunjung disuguhkan dengan informasi villa, diantaranya yaitu layanan, aktivitas, photo slide, serta informasi kontak villa.

\subsection{Uji Coba Aplikasi Web Augmented Reality Villa}

Uji coba atau unjuk kerja aplikasi web augmented reality villa bertujuan untuk menguji apakah user sudah dapat berinteraksi dengan aplikasi, serta apakah aplikasi sudah dapat menampilkan informasi yang sesuai dengan yang dibutuhkan dan diharapkan. Hasil uji coba yang dilakukan adalah sebagai berikut.

a. Tampilan halaman scan marker adalah halaman yang muncul ketika user menekan tombol scan marker yang terdapat pada menu utama. Ruang tampilan video webcam terdapat pada halaman scan marker untuk melakukan scanning marker. Halaman Scan Marker dapat dilihat pada Gambar 11.

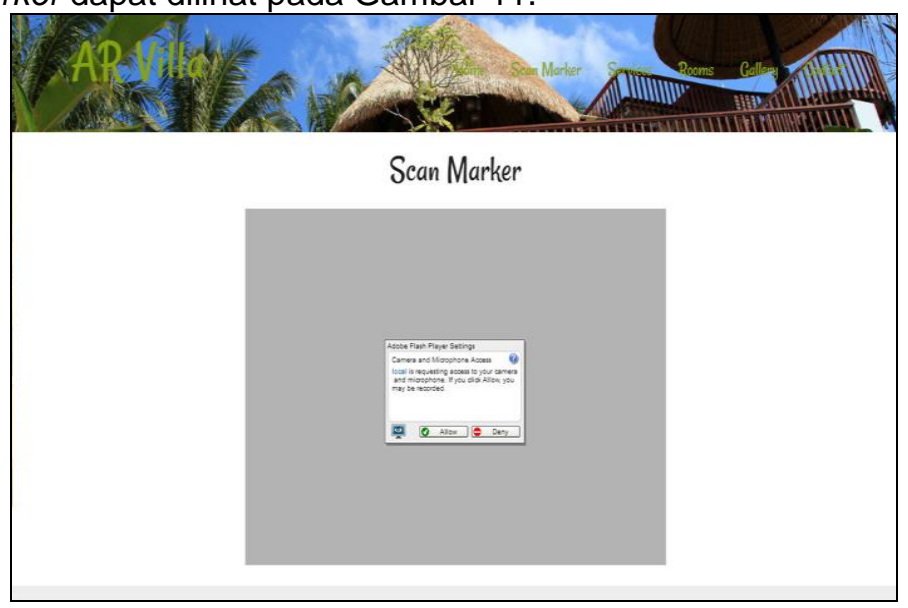

Gambar 11. Tampilan Halaman Scan Marker

Gambar 11 menunjukkan tampilan halaman scan marker. Pengunjung dapat melakukan scanning marker untuk menampilkan objek 3-dimensi villa.

b. User terlebih dahulu menekan tombol allow pada kotak dialog adobe flash player setting unuk mengaktifkan webcam yang terdapat pada ruang tampilan video. Tampilan kotak dialog adobe flash player setting dapat dilihat pada Gambar 12. 


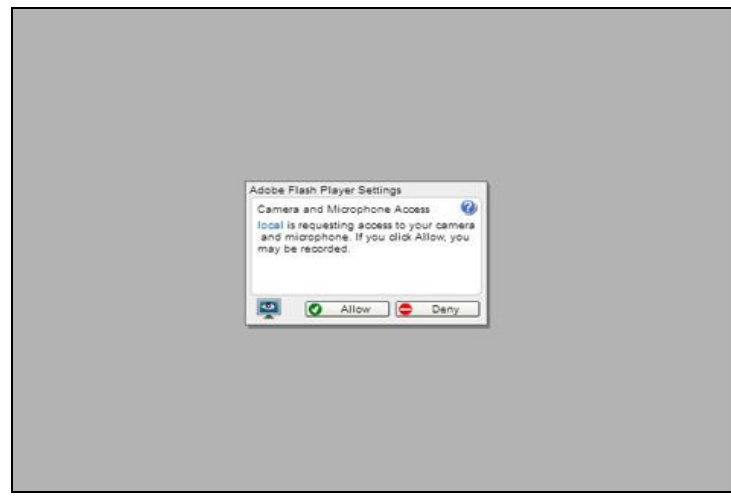

Gambar 12. Tampilan Kotak Dialog Adobe Flash Player Setting

Gambar 12 menunjukkan tampilan kotak dialog adobe flash player setting. Kotak dialog adobe flash player setting berfungsi untuk meminta ijin mengaktifkan webcam.

c. Tahap selanjutnya webcam diarahkan kehadapan marker yang terdapat pada brosur villa. Tampilan video webcam dapat dilihat pada Gambar 13.

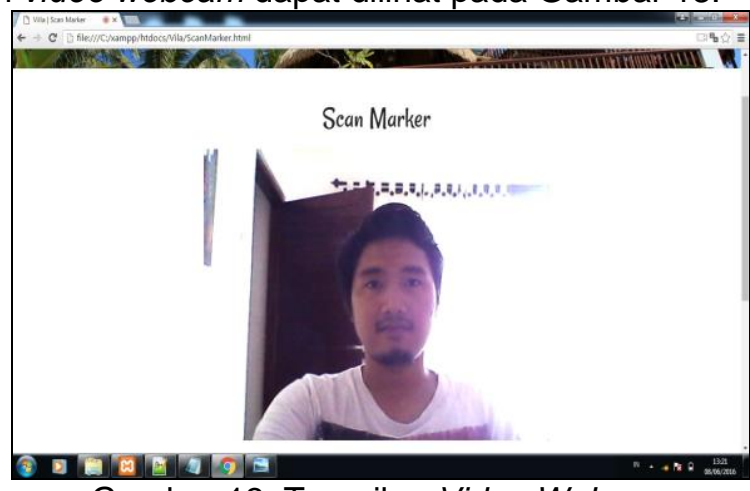

Gambar 13. Tampilan Video Webcam

Gambar 13 menunjukkan tampilan video webcam sudah aktif. Webcam diarahkan pada marker yang terdapat pada brosur.

d. Gambar 14 menampilkan rendering video augmented reality yang menampilkan hasil deteksi marker berupa objek 3-dimensi.

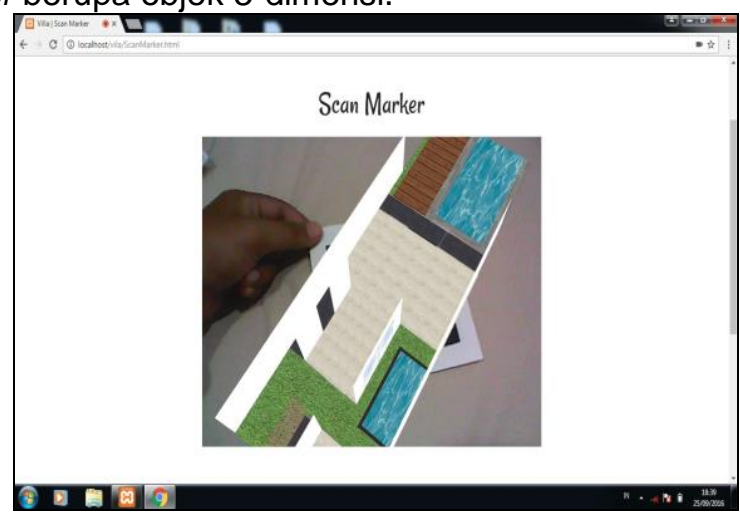

Gambar 14. Tampilan Rendering Video Augmented Reality

Hasil uji coba yang ditampilkan memperlihatkan bahwa Aplikasi Augmented Reality Villa dapat menampilkan objek 3-dimensi villa.

\subsection{Analisa Sistem Aplikasi}

Analisa sistem aplikasi merupakan proses menganalisa dan mengevaluasi sebuah perangkat lunak untuk menguji apakah perangkat lunak sudah memenuhi persyaratan atau belum, dan untuk menentukan perbedaan antara hasil yang diharapkan dengan hasil 
sebenarnya. Analisa sistem dilakukan dengan metode penelitian survey, pengumpulan data, penyajian data dan analisa untuk mengelola data. Berikut dijabarkan aspek pengujian aplikasi web augmented reality villa:

a. Aspek kesesuaian proses aplikasi, uji coba terhadap kebenaran proses aplikasi web augmented reality villa. Pengujian dilakukan dengan melihat kesesuaian output yang dihasilkan aplikasi dengan mengaplikasikannya pada penanda (marker) yang terdapat pada brosur. Aplikasi dijalankan kemudian dilakukan pelacakan terhadap penanda (marker) pada brosur.

b. Aspek desain user interface, uji coba terhadap tampilan aplikasi, kesesuaian fitur scan marker, kemudahan penggunaan aplikasi serta kemampuan perangkat menjalankan aplikasi web augmented reality villa.

\subsection{Perhitungan dan Penyajian Data}

Perhitungan dan penyajian data dilakukan untuk mengetahui hasil akhir dari survey yang telah dilakukan. Berikut merupakan perhitungan dan penyajian data hasil survey.

a. Aspek Kesesuaian Proses

Hasil penilaian dari 15 orang responden mengenai aspek kesesuaian proses aplikasi dapat dilihat pada Tabel 1.

Tabel 1. Aspek Kesesuaian Proses

\begin{tabular}{|l|l|l|l|l|}
\hline \multirow{2}{*}{ Pernyataan } & \multicolumn{4}{c|}{ Penilaian } \\
\cline { 2 - 5 } & Kurang Baik & Cukup Baik & Baik & Sangat Baik \\
\hline $\begin{array}{l}\text { Kesesuaian tampilan AR } \\
\text { pada brosur villa }\end{array}$ & $0 \%$ & $6,6 \%$ & $93,3 \%$ & $0 \%$ \\
\hline Kesesuaian fungsi tombol & $0 \%$ & $13,3 \%$ & $80 \%$ & $6,6 \%$ \\
\hline Rata-rata & $\mathbf{0 \%}$ & $\mathbf{9 , 9} \%$ & $\mathbf{8 6 , 6} \%$ & $\mathbf{3 , 3} \%$ \\
\hline
\end{tabular}

Hasil perhitungan rata-rata dari penilaian aspek kesesuaian proses aplikasi dapat dilihat pada Gambar 15 yang menunjukkan diagram aspek kesesuaian proses.

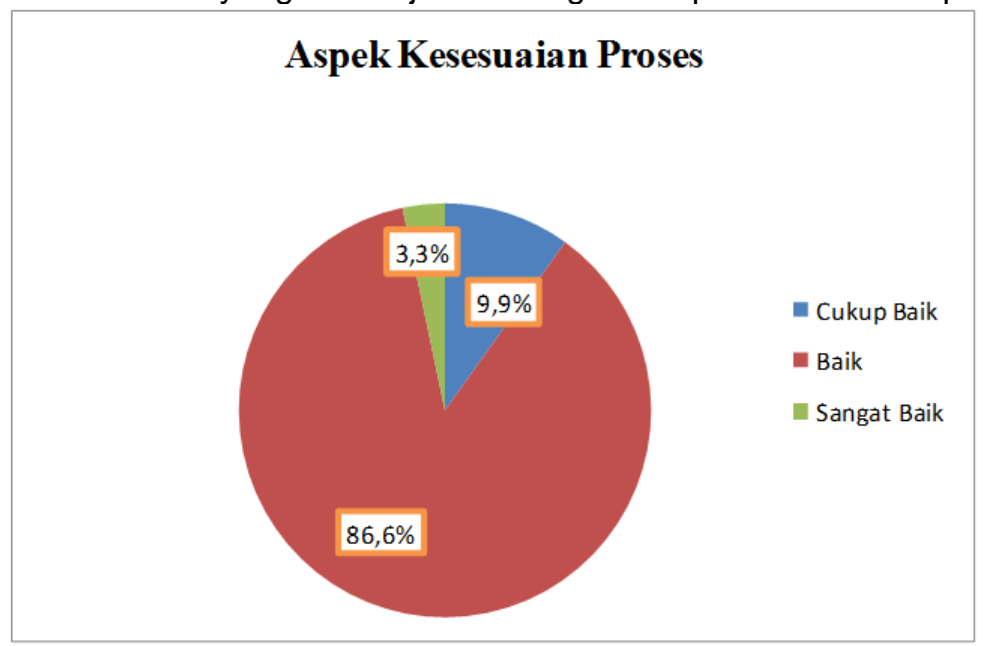

Gambar 15. Diagram Aspek Kesuaian Proses

Gambar 15 menunjukkan bahwa aspek kesesuaian proses memperoleh rata-rata tertinggi pada jawaban baik sebesar $86,6 \%$. Berdasarkan besaran tersebut dapat diartikan bahwa kesesuaian proses aplikasi sudah berjalan dengan baik.

b. Aspek User Interface dan Fitur

Hasil penilaian dari 15 orang responden mengenai aspek user interface dan fitur aplikasi dapat dilihat pada Tabel 2. 
Tabel 2. Aspek User Interface dan Fitur

\begin{tabular}{|l|l|l|l|l|}
\hline \multirow{2}{*}{ Pernyataan } & \multicolumn{4}{c|}{ Penilaian } \\
\cline { 2 - 5 } & Kurang Baik & Cukup Baik & Baik & Sangat Baik \\
\hline Kesesuaian fitur scan marker & $0 \%$ & $6,6 \%$ & $\begin{array}{l}87,6 \\
\%\end{array}$ & $6,6 \%$ \\
\hline $\begin{array}{l}\text { Kemudahan menggunakan } \\
\text { Aplikasi }\end{array}$ & $0 \%$ & $6,6 \%$ & $60 \%$ & $33,3 \%$ \\
\hline $\begin{array}{l}\text { Aplikasi dapat berjalan } \\
\text { dengan baik }\end{array}$ & $0 \%$ & $6,6 \%$ & $60 \%$ & $33,3 \%$ \\
\hline Rata-rata & $\mathbf{0 \%}$ & $\mathbf{6 , 6 \%}$ & $\mathbf{6 9 , 2} \%$ & $\mathbf{2 4 , 4 \%}$ \\
\hline
\end{tabular}

Hasil perhitungan rata-rata dari penilaian aspek user interface dan fitur aplikasi dapat dilihat pada Gambar 16 yang menunjukkan diagram aspek user interface dan fitur.

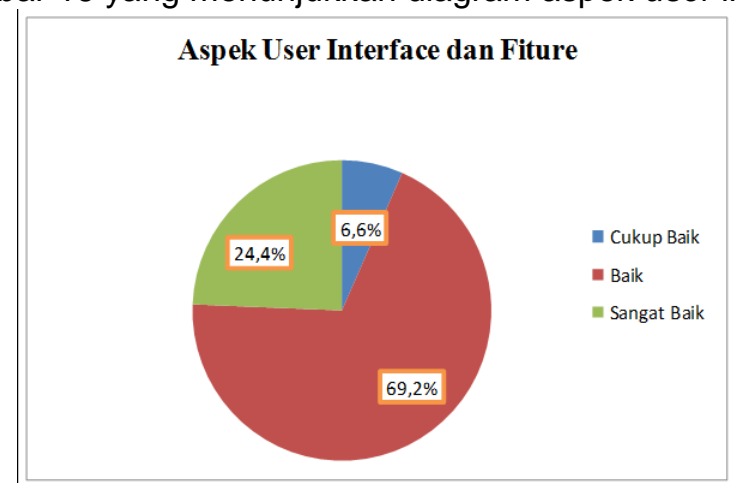

Gambar 16. Diagram Aspek User Interface dan Fitur

Aspek user interface dan fitur memperoleh rata-rata tertinggi pada jawaban baik sebesar $69,2 \%$ dan nilai tertinggi kedua sebesar $24,4 \%$ pada jawaban sangat baik. Berdasarkan besaran tersebut dapat diartikan bahwa user interface dan fitur aplikasi sudah berjalan dengan baik, jadi aplikasi web augmented reality villa ini mudah dipahami dan mudah digunakan.

\section{Kesimpulan}

Berdasarkan hasil uji coba dan analisis dari Aplikasi Web Augmented Reality Villa dapat disimpulkan beberapa hal, yaitu Aplikasi Web Augmented Reality Villa mampu menampilkan objek 3-dimensi interior dan exterior villa, serta dapat menjadi sarana penunjang untuk media informasi baru dan memberikan pengalaman baru bagi pengunjung.

\section{Daftar Pustaka}

[1] Utama IGBR, Strategi Menuju Pariwisata Bali yang Berkualitas, Jurnal Kajian Bali. 2013; $3(2)$.

[2] Dhiyatmika IDGW, Putra IKGD, Mandenni NMIM, Aplikasi Augmented Reality Magic Book Pengenalan Binatang untuk Siswa TK, Jurnal Lontar Komputer. 2015; 6(2).

[3] Bauset VF, Performance Characterization on Mobile Phones for Collaborative Augmented Reality Applications. International Symposium on Distributed Simulation and Real Time Application, Jurnal IEEE Computer Society. 2011; 52-53.

[4] Setiawan SIA, Google SketchUp Perangkat Alternatif dalam Pemodelan 3D, Jurnal Ultimatics. 2011; 3(2).

[5] Hasrul, Desain Media Pembelajaran Animasi Berbasis Adobe Flash Cs3 pada Mata Kuliah Instalasi Listrik 2, Jurnal MEDTEK. 2011; 3(2).

[6] Billinghurst $\mathrm{M}$, The Magic Book-movingseamlessly between reality and virtuality, Jurnal IEEE Computer Society. 2001; 7(5).

[7] Rahman A, Coastera EFF, Rancang Bangun Aplikasi Informasi Universitas Bengkulu sebagai Panduan Pengenalan Kampus Berbasis Android, Jurnal Teknik Informatika. 2014; $7(2)$. 